\title{
A Comparative Effectiveness Study of Renal Parameters Between Imidapril and Amlodipine in Patients with Hypertension: A Retrospective Cohort Study
}

Yayoi Nishida $\cdot$ Yasuo Takahashi $\cdot$ Kotoe Tezuka $\cdot$ Satoshi Takeuchi •

Tomohiro Nakayama · Satoshi Asai

Received: November 1, 2016 / Published online: January 2, 2017

(C) The Author(s) 2016. This article is published with open access at Springerlink.com

\begin{abstract}
Introduction: Imidapril is an angiotensin converting enzyme inhibitor (ACEI) that is frequently used as an antihypertensive drug in Japan. Although ACEIs are known to have adverse effects of decreasing glomerular
\end{abstract}

Enhanced content To view enhanced content for this article go to http://www.medengine.com/Redeem/ BF47F06042596BF7.

Y. Nishida $\cdot$ Y. Takahashi $(\bowtie) \cdot$ K. Tezuka Division of Genomic Epidemiology and Clinical Trials, Clinical Trials Research Center, Nihon University School of Medicine, 30-1

Oyaguchi-Kamimachi, Itabashi-ku, Tokyo 173-8610, Japan

e-mail: takahashi.yasuo@nihon-u.ac.jp

S. Takeuchi · S. Asai

Division of Pharmacology, Department of

Biomedical Sciences, Nihon University School of Medicine, 30-1 Oyaguchi-Kamimachi, Itabashi-ku, Tokyo 173-8610, Japan

T. Nakayama

Division of Laboratory Medicine, Department of Pathology and Microbiology, Nihon University School of Medicine, 30-1 Oyaguchi-Kamimachi, Itabashi-ku, Tokyo 173-8610, Japan

T. Nakayama

Division of Companion Diagnostics, Department of Pathology and Microbiology, Nihon University School of Medicine, 30-1 Oyaguchi-Kamimachi, Itabashi-ku, Tokyo 173-8610, Japan filtration rate (GFR) and causing hyperkalemia, there are very few clinical data on the long-term effect of imidapril on glomerular function. We conducted a retrospective cohort study using a clinical database to evaluate and compare the long-term effects of imidapril and amlodipine on renal parameters in Japanese hypertensive patients in routine clinical practice.

Methods: We identified cohorts of new users of imidapril $(n=57)$ and a propensity score-matched group with an equal number of new users of amlodipine $(n=57)$. We used a multivariable regression model to evaluate and compare the effects of the drugs on laboratory parameters including serum levels of creatinine, potassium, sodium, blood urea nitrogen, and estimated GFR (eGFR) between imidapril users and amlodipine users up to 12 months after the initiation of study drug administration. The mean exposure of imidapril and amlodipine was 226.2 and 235.2 days, respectively.

Results: We found a significant increase of serum creatinine and potassium levels and a decrease of eGFR in imidapril users from the baseline period to the exposure period. The reduction of eGFR and the increase of serum creatinine and potassium levels in imidapril 
users were significantly greater than those in amlodipine users.

Conclusions: Our study showed that imidapril decreased eGFR and increases the serum levels of creatinine and potassium compared with amlodipine, at least during 1 year of administration.

Keywords: Amlodipine; eGFR; Hypertension; Imidapril; Serum creatinine; Serum potassium

\section{INTRODUCTION}

Angiotensin converting enzyme inhibitors (ACEIs) are one of the most frequently used type of antihypertensive drugs. Recent clinical trials reported that ACEIs improve microalbuminuria and prevent the progression of diabetic nephropathy [1-4]. On the other hand, the use of ACEIs may also be associated with the syndrome of "functional renal sufficiency" and hyperkalemia [5]. Therefore, various guidelines recommend that patients treated with ACEIs should be monitored for decreased glomerular filtration rate (GFR) and hyperkalemia, especially those with chronic kidney disease (CKD) [6-8].

Imidapril is an ACEI that is used in the treatment of essential hypertension, renal parenchymal hypertension, and diabetic nephropathy associated with type 1 diabetes mellitus (DM) in Japan [1]. Several studies reported that treatment with imidapril significantly decreased urinary albumin excretion or urinary protein in patients with diabetic nephropathy or chronic glomerulonephritis [9-11]. However, few studies have reported the long-term effect of imidapril on renal parameters in hypertensive patients, especially in those without severe renal dysfunction. Therefore, we evaluated the long-term effectiveness of imidapril on laboratory parameters, including eGFR, serum creatinine, potassium, sodium, and blood urea nitrogen (BUN), in patients with mild to moderate hypertension. On the other hand, L-type calcium channel blockers (CCBs), including amlodipine, have little effect on renal function. Our previous study suggested that CCBs did not affect renal parameters [12]. Lewis et al. reported that the effect of amlodipine on serum creatinine level did not differ from that of placebo in hypertensive patients with type 2 DM [13]. Therefore, we used amlodipine as a control, and compared renal parameters in imidapril users and amlodipine users. The purpose of this study was to evaluate and compare the long-term effects of imidapril and amlodipine on laboratory parameters and electrolytes in Japanese hypertensive patients in routine clinical practice.

\section{METHODS}

\section{Data Source}

This study was a retrospective cohort study using a clinical database. We used data from the Nihon University School of Medicine (NUSM) Clinical Data Warehouse (CDW) for this study. NUSM's CDW is a centralized data repository that integrates separate databases, including an order entry database and a laboratory results database, from the hospital information systems at three hospitals affiliated with NUSM; Nihon University Itabashi Hospital, Nerima Hikarigaoka Hospital, and Surugadai Nihon University Hospital. The prescribing data of over 0.7 million patients are linked longitudinally to detailed clinical information such as patient demographics, diagnosis, and 
laboratory data. To protect patient privacy, patient identifiers are replaced with anonymous identifiers in all databases of this CDW. Several epidemiological studies examining the effects of drugs on glucose and lipid metabolism, serum uric acid and renal function using NUSM's CDW have been published [12, 14-16].

\section{Study Populations}

We examined Japanese patients with mild to moderate hypertension aged over 20 years, who had been newly treated with imidapril or amlodipine for at least 3 months between December 1, 2004 and May 31, 2012. We identified 4853 hypertensive patients treated with imidapril and 22,889 with amlodipine. We excluded patients with moderate to severe renal failure $(e G F R<60)$ and patients who had missing serum creatinine data during the study period. We also excluded patients treated with an ACEI other than imidapril, a $\mathrm{CCB}$ other than amlodipine, an $\mathrm{ARB}$, renin inhibitor, antihypertensive diuretic, treatment for CKD, or treatment with a potassium or sodium preparation during the study period. The study population for imidapril was 66 and for amlodipine was 835 . We identified an equal number of patients in the imidapril group ( $n=57, \quad 0.63-10 \mathrm{mg} /$ day) and a propensity score-matched sample of the amlodipine group ( $n=57,2.5-10 \mathrm{mg} /$ day), and compared them. The experimental protocol was approved by the Ethical Committee of Nihon University School of Medicine, and the study was conducted in compliance with the Ethical Guidelines for Medical and Health Research Involving Human Subjects of the Ministry of Education, Culture, Sports, Science, and Technology and Ministry of Health, Labour, and Welfare, Japan [17].
This article is based on previously conducted studies and does not involve any new studies of human or animal subjects performed by any of the authors.

\section{Exposure and Measurements}

The baseline measurement period (non-exposure period) was defined as within 12 months before the start of imidapril or amlodipine treatment. The exposure period (outcome measurement period) was defined as between 2 and 12 months after the start of imidapril or amlodipine treatment. The mean exposure of imidapril users and amlodipine users was 226.2 and 235.2 days, respectively (Table 1). Blood test data for outcomes (serum creatinine, blood urea nitrogen; BUN, serum potassium and sodium) were collected for each individual at the date nearest the start of imidapril or amlodipine treatment in the baseline period, and at the date nearest 12 months after the start of imidapril or amlodipine treatment in the exposure period. Blood test data other than creatinine included several missing values (comprising $2.6-7.0 \%$ of the entire target). eGFR was calculated according to the formula for Japanese specified by the Japan Society of Nephrology: eGFR (mL/ $\left.\mathrm{min} / 1.73 \mathrm{~m}^{2}\right)=194 \times \mathrm{SCr}^{-1.094} \times \mathrm{Age}^{-0.287}$ $(\times 0.739$ if female) [18].

\section{Data Elements}

For each patient, we collected information on patient demographics (age and sex), medical history, and use of medication as baseline covariates for adjustment. Medical history included cerebrovascular disease (ICD-10 code; I60-69), ischemic heart disease (I20-I25), other heart disease (I30-I52), malignant neoplasm (C00-C97), liver disease (K70-K77), kidney 
Table 1 Baseline characteristics before and after propensity score matching

\begin{tabular}{|c|c|c|c|c|c|c|}
\hline \multirow[t]{2}{*}{ Covariates } & \multicolumn{3}{|l|}{ Before matching } & \multicolumn{3}{|l|}{ After matching } \\
\hline & $\begin{array}{l}\text { Imidapril } \\
(n=66), n(\%)\end{array}$ & $\begin{array}{l}\text { Amlodipine } \\
(n=835), n(\%)\end{array}$ & $p$ value & $\begin{array}{l}\text { Imidapril } \\
(n=57), n(\%)\end{array}$ & $\begin{array}{l}\text { Amlodipine } \\
(n=57), n(\%)\end{array}$ & $p$ value \\
\hline $\begin{array}{l}\text { Exposure days (days, } \\
\text { mean } \pm \text { SE) }\end{array}$ & $223.8 \pm 12.7$ & $234 \pm 3.5$ & 0.4358 & $226.2 \pm 13.8$ & $235.2 \pm 13.0$ & 0.6359 \\
\hline $\begin{array}{l}\text { Age (years, } \\
\text { mean } \pm S E)\end{array}$ & $60.3 \pm 12.6$ & $64.3 \pm 11.4$ & $0.0068^{*}$ & $61.2 \pm 1.7$ & $63.2 \pm 1.9$ & 0.4178 \\
\hline Women & $30(45.5)$ & $528(63.2)$ & $0.0042^{*}$ & $29(50.9)$ & $27(47.4)$ & 0.7079 \\
\hline \multicolumn{7}{|l|}{ Medical history } \\
\hline $\begin{array}{l}\text { Cerebrovascular } \\
\text { disease }\end{array}$ & $16(24.2)$ & $199(23.8)$ & 0.94 & $15(26.3)$ & $17(29.8)$ & 0.6768 \\
\hline $\begin{array}{l}\text { Ischemic heart } \\
\text { disease }\end{array}$ & $37(56.1)$ & $262(31.4)$ & $<0.0001^{*}$ & $28(49.1)$ & $27(47.4)$ & 0.8513 \\
\hline Other heart disease & $23(34.9)$ & $200(24)$ & $0.0483^{*}$ & $18(31.6)$ & $23(40.4)$ & 0.3292 \\
\hline $\begin{array}{c}\text { Malignant } \\
\text { neoplasm }\end{array}$ & $27(40.9)$ & $493(59)$ & $0.0041^{*}$ & $26(45.6)$ & $23(40.4)$ & 0.5703 \\
\hline Liver disease & $25(37.9)$ & $395(47.3)$ & 0.1394 & $25(43.9)$ & $24(42.1)$ & 0.8499 \\
\hline Kidney disease & $20(30.3)$ & $285(34.1)$ & 0.5269 & $18(31.6)$ & $19(33.3)$ & 0.8415 \\
\hline Hyperlipidemia & $41(62.1)$ & $354(42.4)$ & $0.0019^{*}$ & $35(61.4)$ & $34(59.7)$ & 0.848 \\
\hline Diabetes mellitus & $43(65.2)$ & $505(60.5)$ & 0.4541 & $37(64.9)$ & $45(79)$ & 0.0954 \\
\hline \multicolumn{7}{|l|}{ Medication } \\
\hline \multicolumn{7}{|l|}{ Antidiabetic drugs } \\
\hline Insulin & $5(7.6)$ & $27(3.2)$ & 0.0665 & $5(8.8)$ & $6(10.5)$ & 0.7511 \\
\hline $\begin{array}{l}\text { Oral antidiabetic } \\
\text { drugs }\end{array}$ & $10(15.2)$ & $81(9.7)$ & 0.1571 & $10(17.5)$ & $19(33.3)$ & 0.0529 \\
\hline \multicolumn{7}{|l|}{ Antidyslidemic drugs } \\
\hline Statins & $25(37.9)$ & $186(22.3)$ & $0.004^{*}$ & $22(38.6)$ & $20(35.1)$ & 0.6978 \\
\hline Fibrates & $2(3)$ & $17(2)$ & 0.5883 & $2(3.5)$ & $2(3.5)$ & 1 \\
\hline $\begin{array}{l}\text { Other } \\
\text { antidyslidemic } \\
\text { drugs }\end{array}$ & $2(3)$ & $43(5.2)$ & 0.4467 & $2(3.5)$ & $1(1.8)$ & 0.5585 \\
\hline Chemotherapeutics & $3(4.6)$ & $78(9.3)$ & 0.1898 & $3(5.3)$ & $1(1.8)$ & 0.3087 \\
\hline $\begin{array}{c}\text { Liver disease } \\
\text { therapeutics }\end{array}$ & $2(3)$ & $65(7.8)$ & 0.1564 & $2(3.5)$ & $4(7)$ & 0.4015 \\
\hline Steroids & $5(7.6)$ & $119(14.3)$ & 0.1296 & $5(8.8)$ & $3(5.3)$ & 0.4634 \\
\hline NSAIDs & $42(63.6)$ & $331(39.6)$ & $0.0001^{*}$ & $34(59.7)$ & $32(56.1)$ & 0.7044 \\
\hline
\end{tabular}


Table 1 continued

\begin{tabular}{llllllll}
\hline Covariates & \multicolumn{2}{l}{ Before matching } & & & After matching \\
\cline { 2 - 3 } & $\begin{array}{l}\text { Imidapril } \\
(\boldsymbol{n}=\mathbf{6 6}), \boldsymbol{n}(\%)\end{array}$ & $\begin{array}{l}\text { Amlodipine } \\
(\boldsymbol{n}=\mathbf{8 3 5}), \boldsymbol{n}(\%)\end{array}$ & $\boldsymbol{p}$ value & & $\begin{array}{l}\text { Imidapril } \\
(\boldsymbol{n}=\mathbf{5 7}), \boldsymbol{n}(\%)\end{array}$ & $\begin{array}{l}\text { Amlodipine } \\
(\boldsymbol{n}=\mathbf{5 7}), \boldsymbol{n}(\%)\end{array}$ & $\boldsymbol{p}$ value \\
\hline Antihypertensive drugs & & & & & & & \\
$\alpha$-blockers & $0(0)$ & $17(2)$ & 0.2419 & $0(0)$ & $0(0)$ & - \\
$\beta$-blockers & $5(7.6)$ & $44(5.3)$ & 0.4264 & $4(7)$ & $5(8.8)$ & 0.7283 \\
$\alpha+\beta$-blockers & $4(6.1)$ & $26(3.1)$ & 0.1989 & $4(7)$ & $5(8.8)$ & 0.7283 \\
Vasodilators & $0(0)$ & $13(1.6)$ & 0.3072 & $0(0)$ & $0(0)$ & - \\
\hline
\end{tabular}

Data are numbers of individuals (\%) unless otherwise stated

NSAID non-steroidal anti-inflammatory drug

${ }^{*} p<0.05$ (imidapril vs amlodipine, $t$ test for continuous variables and Chi-squared test for categorical data)

disease (N00-N19), hyperlipidemia (E78.0-E78.5), and DM (E10-E14) during the 365 days preceding the first date of administration of imidapril or amlodipine. Drugs used during the 90 days before the start of imidapril or amlodipine treatment included other antihypertensive drugs ( $\alpha$-blockers, $\beta$-blockers, $\alpha+\beta$-blockers and vasodilators), insulin, oral hypoglycemic drugs, lipid-lowering drugs (including statins, fibrates, and other lipid-lowering drugs), chemotherapeutic drugs, liver disease therapeutics, steroids, and non-steroidal anti-inflammatory drugs.

\section{Statistical Analysis}

All statistical analyses were performed using SAS software, version 9.3 (SAS Institute Inc., Cary, NC, USA). This study was a retrospective observational study, and because the non-randomized subjects had inherent issues of selection bias and confounding factors, we used a propensity score method to minimize selection bias and a multivariable regression model to measure the effect of imidapril and amlodipine on blood test results while controlling for baseline confounders. We used propensity score matching (greedy 1:1 matching) to reduce bias by balancing covariates between settings. The details of the propensity score method are described elsewhere [19-22]. In brief, the propensity score for each subject was obtained by fitting a logistic regression model that included the predictor variable as an outcome and all the baseline covariates in Table 1. After the propensity score was constructed, we matched the propensity score of each user of imidapril and amlodipine. A nearest-neighbor-matching algorithm with a "greedy" heuristic was used to match patients and the logit of their propensity score [23]. After propensity score matching, we used $t$ test for continuous variables and Chi-squared test for categorical data to compare differences in baseline characteristics between imidapril and amlodipine users. A paired $t$ test was used to compare the mean values at baseline and during the exposure period in imidapril and amlodipine users. A covariate-adjusted mixed linear model was to compare the adjusted least-square mean change from the baseline value to the exposure value between imidapril and amlodipine users. The covariates used in the adjusted model included age, sex, medical history, and previous 
Table 2 Antihypertensive drugs during exposure periods

\begin{tabular}{llll}
\hline $\begin{array}{l}\text { Antihypertensive } \\
\text { drugs }\end{array}$ & $\begin{array}{l}\text { Imidapril, } \\
\boldsymbol{n}(\%)\end{array}$ & $\begin{array}{l}\text { Amlodipine, } \\
\boldsymbol{n}(\%)\end{array}$ & $\boldsymbol{p}$ value \\
\hline Alpha blockers & $0(0)$ & $0(0)$ & - \\
Beta blockers & $6(10.5)$ & $7(12.3)$ & 0.7683 \\
$\begin{array}{l}\text { Alpha + beta } \\
\text { blockers }\end{array}$ & $4(7)$ & $5(8.8)$ & 0.7283 \\
Vasodilators & $0(0)$ & $0(0)$ & - \\
\hline
\end{tabular}

$p$ values are for imidapril vs. amlodipine

medication, as listed in Table 1 . All reported $p$ values of less than 0.05 were considered to indicate statistical significance.

\section{RESULTS}

Table 1 shows the baseline characteristics of patients who had been treated with imidapril and amlodipine, before and after propensity score matching. After propensity score matching, there was no statistically difference in baseline characteristics between imidapril and amlodipine users. The mean age was 61.2 and 63.2 years, and $50.9 \%$ and $47.4 \%$ of imidapril and amlodipine users were female, respectively. In imidapril users and amlodipine users, $7.0 \%$ and $8.8 \%$ were currently using a $\beta$-blocker, and $7.0 \%$ and $8.8 \%$ were using an $\alpha+\beta$-blocker, respectively. Table 2 shows the antihypertensive drugs used during the exposure period. There was no significant difference in use of any other antihypertensive drugs between imidapril and amlodipine users. Table 3 shows baseline laboratory parameters after propensity score matching. There was no significant difference in any laboratory parameter, including serum creatinine, potassium, and sodium, BUN, and eGFR, between imidapril and amlodipine users.

Table 4 shows laboratory parameters at baseline and during the exposure period. In imidapril users, serum creatinine and potassium levels were significantly increased, and eGFR was significantly decreased during the exposure period compared with the baseline period. BUN and sodium level did not significantly change during the exposure period compared with the baseline period in imidapril users. In amlodipine users, there was no significant change in any laboratory parameter during the exposure period compared with the baseline period.

Table 5 shows the mean changes in laboratory parameters during the exposure period from the baseline period. The increase

Table 3 Baseline laboratory parameters in hypertensive patients administered imidapril or amlodipine

\begin{tabular}{|c|c|c|c|c|c|c|c|}
\hline \multirow[t]{2}{*}{ Laboratory parameters } & \multicolumn{3}{|c|}{ Imidapril } & \multicolumn{3}{|c|}{ Amlodipine } & \multirow[t]{2}{*}{$p$ value } \\
\hline & $\bar{N}$ & Mean & $95 \% \mathrm{CI}$ & $\bar{N}$ & Mean & $95 \% \mathrm{CI}$ & \\
\hline Creatinine $(\mathrm{mg} / \mathrm{dL})$ & 57 & 0.62 & $(0.59,0.65)$ & 57 & 0.64 & $(0.62,0.67)$ & 0.1833 \\
\hline $\mathrm{eGFR}\left(\mathrm{mL} / \mathrm{min} / 1.73 \mathrm{~m}^{2}\right)$ & 57 & 77.1 & $(73.5,80.7)$ & 57 & 73.1 & $(69.7,76.5)$ & 0.1069 \\
\hline $\mathrm{BUN}(\mathrm{mg} / \mathrm{dL})$ & 56 & 13.3 & $(12.3,14.3)$ & 55 & 12.6 & $(11.7,13.6)$ & 0.3241 \\
\hline Sodium $(\mathrm{mEq} / \mathrm{L})$ & 54 & 140 & $(140,141)$ & 52 & 141 & $(140,142)$ & 0.4713 \\
\hline Potassium (mEq/L) & 54 & 4.1 & $(4.0,4.3)$ & 52 & 4.1 & $(4.0,4.2)$ & 0.8763 \\
\hline
\end{tabular}

$p$ values are for imidapril vs. amlodipine (Student's $t$ test)

eGFR estimated glomerular filtration rate, $B U N$ blood urea nitrogen, $C I$ confidence interval 
Table 4 Mean levels of laboratory parameters at baseline and during exposure period

\begin{tabular}{|c|c|c|c|c|c|c|c|c|}
\hline \multirow[t]{2}{*}{ Laboratory parameters } & \multicolumn{4}{|c|}{ Imidapril } & \multicolumn{4}{|c|}{ Amlodipine } \\
\hline & $N$ & Mean & $95 \% \mathrm{CI}$ & $p$ value & $N$ & Mean & $95 \% \mathrm{CI}$ & $p$ value \\
\hline \multicolumn{9}{|l|}{ Creatinine $(\mathrm{mg} / \mathrm{dL})$} \\
\hline Baseline & 57 & 0.62 & $(0.59,0.65)$ & Reference & 57 & 0.64 & $(0.62,0.67)$ & Reference \\
\hline Exposure & & 0.67 & $(0.64,0.7)$ & $<0.0001^{*}$ & & 0.65 & $(0.62,0.69)$ & 0.4246 \\
\hline \multicolumn{9}{|l|}{$\operatorname{eGFR}\left(\mathrm{mL} / \mathrm{min} / 1.73 \mathrm{~m}^{2}\right)$} \\
\hline Baseline & 57 & 77.1 & $(73.5,80.7)$ & Reference & 57 & 73.1 & $(69.7,76.5)$ & Reference \\
\hline Exposure & & 71.2 & $(67.6,74.8)$ & $0.0002^{*}$ & & 73.9 & $(68.8,78.9)$ & 0.7031 \\
\hline \multicolumn{9}{|l|}{$\mathrm{BUN}(\mathrm{mg} / \mathrm{dL})$} \\
\hline Baseline & 56 & 13.3 & $(12.3,14.3)$ & Reference & 55 & 12.6 & $(11.7,13.9)$ & Reference \\
\hline Exposure & & 13.9 & $(12.9,14.9)$ & 0.3292 & & 13.6 & $(12.6,14.6)$ & 0.0544 \\
\hline \multicolumn{9}{|l|}{ Sodium $(\mathrm{mEq} / \mathrm{L})$} \\
\hline Baseline & 54 & 140 & $(140,141)$ & Reference & 52 & 141 & $(140,142)$ & Reference \\
\hline Exposure & & 141 & $(140,142)$ & 0.2776 & & 141 & $(140,142)$ & 0.318 \\
\hline \multicolumn{9}{|l|}{ Potassium $(\mathrm{mEq} / \mathrm{L})$} \\
\hline Baseline & 54 & 4.1 & $(4.0,4.3)$ & Reference & 52 & 4.1 & $(4.0,4.2)$ & Reference \\
\hline Exposure & & 4.3 & $(4.3,4.4)$ & $0.0072^{*}$ & & 4.1 & $(4.0,4.2)$ & 0.3704 \\
\hline
\end{tabular}

$e G F R$ estimated glomerular filtration rate, $B U N$ blood urea nitrogen, $C I$ confidence interval

${ }^{*} p<0.05$ (exposure period vs baseline, paired $t$ test)

Table 5 Mean changes in laboratory parameter levels from baseline to exposure period

\begin{tabular}{|c|c|c|c|c|c|c|c|}
\hline \multirow[t]{2}{*}{ Laboratory parameters } & \multicolumn{3}{|c|}{ Imidapri } & \multicolumn{3}{|c|}{ Amlodipine } & \multirow[t]{2}{*}{$p$ value } \\
\hline & $\bar{N}$ & LS mean & 95\% CI & $\bar{N}$ & LS mean & 95\% CI & \\
\hline$\Delta$ Creatinine $(\mathrm{mg} / \mathrm{dL})$ & 57 & 0.053 & $(0.03,0.08)$ & 57 & 0.0084 & $(-0.02,0.03)$ & $0.0138^{*}$ \\
\hline$\Delta \mathrm{eGFR}\left(\mathrm{mL} / \mathrm{min} / 1.73 \mathrm{~m}^{2}\right)$ & 57 & -6.17 & $(-9.53,-2.81)$ & 57 & 1.01 & $(-2.35,4.37)$ & $0.0045^{*}$ \\
\hline$\Delta \mathrm{BUN}(\mathrm{mg} / \mathrm{dL})$ & 56 & 0.31 & $(-0.8,1.41)$ & 55 & 1.20 & $(0.08,2.32)$ & 0.2788 \\
\hline$\Delta$ Sodium $(\mathrm{mEq} / \mathrm{L})$ & 54 & 0.62 & $(-0.31,1.55)$ & 52 & 0.32 & $(-0.64,1.27)$ & 0.66 \\
\hline$\Delta$ Potassium $(\mathrm{mEq} / \mathrm{L})$ & 54 & 0.20 & $(0.06,0.34)$ & 52 & -0.05 & $(-0.19,0.09)$ & $0.0172^{*}$ \\
\hline
\end{tabular}

$e G F R$ estimated glomerular filtration rate, $B U N$ blood urea nitrogen, $L S$ mean least-square mean, $C I$ confidence interval, $\Delta$ mean change in renal parameter level during exposure period from baseline

${ }^{*} p<0.05$ (imidapril vs amlodipine). Analyses were adjusted for covariates including age, sex, medical history and previous medication

of creatinine and potassium level and the reduction of eGFR were significantly greater in imidapril users compared with amlodipine users. The mean changes of serum sodium and BUN level were not significantly different between imidapril and amlodipine users. 


\section{DISCUSSION}

In this study, we evaluated and compared the effect of imidapril and amlodipine on renal parameters including serum creatinine level and eGFR in a long-term administration period up to 12 months. We found a significant increase of serum creatinine and potassium level, and a significant decrease of eGFR from the baseline period to during the exposure period in imidapril users. The increase of serum creatinine and potassium level and reduction of eGFR were significantly greater in imidapril users compared with amlodipine users. These results suggest that imidapril has a slightly unfavorable effect on renal function and electrolyte balance compared with amlodipine.

It is well known that treatment with ACEIs reduces GFR through a vasodilator effect on the efferent arteriole [7]. Acute renal failure is likely to occur especially in patients with renal hypoperfusion, including those with high-grade bilateral renal artery stenosis, because angiotensin II is necessary for maintenance of GFR during states of significant volume depletion [5]. Therefore, various guidelines recommend that patients treated with ACEIs should be monitored for a decrease in GFR, especially patients with CKD [6-8]. Our findings, showing the effects of imidapril treatment, to increase serum creatinine level and decrease eGFR, support these guidelines. Also, hyperkalemia is a common adverse effect with the use of ACEIs [6]. Supporting this, our findings showed an increase in the level of serum potassium in imidapril users. Considering these results, regular checks of GFR and potassium level are needed in users of imidapril, as well as other ACEIs, at least for 1 year after its initiation. However, an increase in creatinine level or a decrease in eGFR may not be of clinical concern and does not always require a reduction in dose or discontinuation, because the mean levels of creatinine and eGFR in this study were within the normal range during the study period in both drug users. In addition, Apperloo et al. suggested that the therapy-induced GFR decline is of hemodynamic and not of structural origin, and this initial GFR decline is associated with subsequent stable renal function [24]. Maschio et al. reported that the serum creatinine concentration in the ACEI, benazepril, group increased more markedly than that in the placebo group during the first 2 months of administration. However, the speed of the increase in creatinine slowed after 2 months, and the serum concentration of creatinine in the benazepril group was lower than that in the placebo group at 12, 24, and 36 months. Meanwhile, urinary protein decreased after 2 months of treatment, and the progression of renal insufficiency was prevented, including the need for dialysis or doubling of the baseline serum creatinine concentration [25]. Similarly to previous reports, the "unfavorable" effect of a decrease in GFR and increase in creatinine might be a transient hemodynamically mediated reduction in glomerular filtration caused by blockade of the renin-angiotensin system and decreased blood pressure. Further study, including longitudinal measurement of microalbuminuria, is needed to determine whether the reduction of eGFR with imidapril therapy is associated with subsequent renal protection in clinical practice.

Very few clinical studies have examined the long-term effect of imidapril on serum creatinine level. The effect of imidapril on serum creatinine level was not significant at 36 months in patients with chronic glomerulonephritis $(n=11)$ [10]. Also, few clinical studies have examined the effect of 
imidapril on renal function in a short-term administration period up to 6 months. Higashi et al. reported that the level of serum creatinine and GFR, which was measured by inulin clearance, remained unchanged after 12 weeks of treatment with imidapril $(n=13)$ in hypertensive patients without renal disease [26]. In hypertensive patients without CKD treated with a high dose of an ARB, valsartan, after adding imidapril $(n=18)$, eGFR tended to decrease, but did not significantly change during 4 months compared with baseline [27]. Fogari et al. reported that imidapril significantly decreased urinary albumin excretion, but there was no significant change in creatinine level up to 24 weeks in diabetic hypertensive patients with microalbuminuria $(n=88)$ [11]. These discrepancies between our study and these previous studies could be explained in part by differences in the duration of treatment, the study population or the study design. Our study included patients with various backgrounds and clinical settings, and used a long-term administration period up to 12 months, and the sample size was over 50 patients. Also, we used sophisticated statistical methods, including a propensity score method and a multivariable regression model to adjust background variables. On the contrary, the small sample size in these previous studies may have led to missing the true effect through the combination of reduced statistical power and increased variance. The study of Fogari et al. seemed to have a sufficient sample size, but they focused on diabetic patients with microalbuminuria. Our study could not evaluate microalbuminuria because of missing data. As an alternative to this issue, we excluded patients with moderate to severe renal failure in order to obtain reliable results, because the impacts of these variables on outcomes were too large to control as baseline variables.
Our study has several limitations. First, this study was a retrospective, non-randomized study with potential for selection bias and confounding factors. We used rigorous statistical methods to control for potential confounding variables between imidapril users and amlodipine users, including propensity score matching and a multivariable regression model. However, their ability to control for differences was limited to variables that were available or measurable. Second, the subjects in this study included patients receiving combination therapy with antihypertensive drugs with other mechanisms. We used the statistical method mentioned above to reduce the influence of other antihypertensive drugs. However, further studies are needed to compare the effect of combination therapy on renal function with that of monotherapy. Third, we did not fix the daily dosage in both imidapril and amlodipine users, because achievement of the blood pressure goal requires various doses of an agent across different individuals or even in the same individual in clinical practice. This study was not designed to assess the effects of imidapril and amlodipine at each dosage, because it is difficult to determine whether or not pharmacodynamics are dose-dependent in clinical settings. Fourth, we should consider the natural reduction of renal function in hypertensive patients, because it is well known that renal function declines gradually in patients with hypertension [28, 29]. Our study showed no significant change of any parameter from the baseline period to during the exposure period in amlodipine users, suggesting that the impact of the natural reduction of renal function on the outcomes of this study was small. Fifth, the sample size was small $(N=52-57)$ and might have not enough power to detect a statistically significant change. When sufficient data are accumulated, 
further studies will be needed to determine the effect of imidapril on renal function. Finally, we could not analyze micro- and macroalbuminuria because there were many missing data. When sufficient data including albuminuria are accumulated, further studies will be needed to determine the detailed effect of imidapril on renal function. However, the findings of our comparative effectiveness study, using a sophisticated statistical method in a real-world setting, are reliable and relevant to clinical practice.

\section{CONCLUSION}

In this study, we observed a greater reduction of eGFR and increase of serum creatinine and potassium levels in patients with mild to moderate hypertension who had received imidapril compared with amlodipine for at least up to 1 year. Our findings suggest that imidapril treatment slightly decreases eGFR and increases the serum levels of creatinine and potassium, and support the experience noted in clinical practice that regular checks of serum creatinine and electrolyte levels should be performed prior to and after ACEI initiation.

\section{ACKNOWLEDGEMENTS}

This work was supported by the Health Sciences Research Institute, Inc., Yokohama, Japan and Convergence CT Japan KK., Tokyo, Japan. No funding or sponsorship was received for publication of this article. All named authors meet the International Committee of Medical Journal Editors (ICMJE) criteria for authorship for this manuscript, take responsibility for the integrity of the work as a whole, and have given final approval to the version to be published.
Disclosures. Yayoi Nishida, Yasuo Takahashi, Kotoe Tezuka, Satoshi Takeuchi, Tomohiro Nakayama, and Satoshi Asai have nothing to disclose.

Compliance with ethics guidelines. This article is based on previously conducted studies, and does not involve any new studies of human or animal subjects performed by any of the authors.

Open Access. This article is distributed under the terms of the Creative Commons Attribution-NonCommercial 4.0 International License (http://creativecommons.org/licenses/ by-nc/4.0/), which permits any noncommercial use, distribution, and reproduction in any medium, provided you give appropriate credit to the original author(s) and the source, provide a link to the Creative Commons license, and indicate if changes were made.

\section{REFERENCES}

1. Robinson DM, Curran MP, Lyseng-Williamson KA. Imidapril: a review of its use in essential hypertension, type 1 diabetic nephropathy and chronic heart failure. Drugs. 2007;67:1359-78.

2. Maschio G, Alberti D, Locatelli F, et al. Angiotensin-converting enzyme inhibitors and kidney protection: the AIPRI trial. J Cardiovasc Pharmacol. 1999;33(Suppl 1):S16-20 (discussion S41-43).

3. Ruggenenti P, Fassi A, Ilieva AP, et al. Preventing microalbuminuria in type 2 diabetes. $\mathrm{N}$ Engl J Med. 2004;351:1941-51.

4. Song JC, White CM. Clinical pharmacokinetics and selective pharmacodynamics of new angiotensin converting enzyme inhibitors: an update. Clin Pharmacokinet. 2002;41(3):207-24.

5. Schoolwerth AC, Sica DA, Ballermann BJ, Wilcox CS, Council on the Kidney in Cardiovascular Disease and the Council for High Blood Pressure Research of the American Heart Association. Renal considerations in angiotensin converting enzyme 
inhibitor therapy: a statement for healthcare professionals from the Council on the Kidney in Cardiovascular Disease and the Council for High Blood Pressure Research of the American Heart Association. Circulation. 2001;104:1985-91.

6. Kidney Disease Outcomes Quality Initiative (K/ DOQI). K/DOQI clinical practice guidelines on hypertension and antihypertensive agents in chronic kidney disease. Am J Kidney Dis. 2004;43(5 Suppl 1):S1-290.

7. Kidney Disease: Improving Global Outcomes (KDIGO) Management of Blood Pressure Work Group. KDIGO clinical practice guideline for the management of blood pressure in chronic kidney disease. Kidney Int Suppl (2011). 2012;2:337-414.

8. Shimamoto K, Ando K, Fujita T, et al. The Japanese Society of Hypertension Guidelines for the Management of Hypertension (JSH 2014). Hypertens Res. 2014;37(4):253-390.

9. Katayama S, Kikkawa R, Isogai S, et al. Effect of captopril or imidapril on the progression of diabetic nephropathy in Japanese with type 1 diabetes mellitus: a randomized controlled study (JAPAN-IDDM). Diabetes Res Clin Pract. 2002;55:113-21.

10. Satonaka H, Suzuki E, Hayakawa H, et al. Long-term effect of imidapril hydrochloride compared with dilazep hydrochloride administration on blood pressure and renal function in patients with chronic glomerulonephritis. Int Heart J. 2005;46:701-10.

11. Fogari R, Mugellini A, Zoppi A, et al. Effect of imidapril versus ramipril on urinary albumin excretion in hypertensive patients with type 2 diabetes and microalbuminuria. Expert Opin Pharmacother. 2013;14:2463-73.

12. Nishida $\mathrm{Y}$, Takahashi $\mathrm{Y}$, Nakayama $\mathrm{T}$, Asai $\mathrm{S}$. Comparative effect of angiotensin II type I receptor blockers and calcium channel blockers on laboratory parameters in hypertensive patients with type 2 diabetes. Cardiovasc Diabetol. 2012;11:53.

13. Lewis EJ, Hunsicker LG, Clarke WR, et al. Renoprotective effect of the angiotensin-receptor antagonist irbesartan in patients with nephropathy due to type 2 diabetes. $\mathrm{N}$ Engl J Med. 2001;345(12):851-60.

14. Susa N, Nishida Y, Yada Y, Nakayama T, Asai S, Takahashi Y. Comparative effect of fixed-dose combination tablets of candesartan cilexetil/ amlodipine versus olmesartan medoxomil/ azelnidipine on laboratory parameters in patients with hypertension: a retrospective cohort study. Clin Exp Hypertens. 2016;38(2):173-9.
15. Takahashi Y, Nishida Y, Nakayama T, Asai S. Adverse effect profile of trichlormethiazide: a retrospective observational study. Cardiovasc Diabetol. 2011;10:45.

16. Nishida Y, Takahashi $\mathrm{Y}$, Susa N, Kanou N, Nakayama T, Asai S. Comparative effect of angiotensin II type I receptor blockers on serum uric acid in hypertensive patients with type 2 diabetes mellitus: a retrospective observational study. Cardiovasc Diabetol. 2013;12:159.

17. Ministry of Education, Culture, Sports, Science and Technology and Ministry of Health, Labour and Welfare: Ethical Guidelines for Medical and Health Research Involving Human Subjects. http://www. mhlw.go.jp/file/06-Seisakujouhou-10600000-Daijin kanboukouseikagakuka/0000080278.pdf. Accessed Oct 12, 2016.

18. Matsuo S, Imai E, Horio M, et al. Revised equations for estimated GFR from serum creatinine in Japan. Am J Kidney Dis. 2009;53:982-92.

19. D'Agostino R. Tutorial on biostatistics: propensity score methods for bias reduction in the comparison of a treatment to a non-randomized control group. Stat Med. 1998;17:2265-81.

20. Rosenbaum PR, Rubin DB. The central role of the propensity score in observational studies for causal effects. Biometrika. 1983;70:41-55.

21. Robins JM, Hernán MA, Brumback B. Marginal structural models and causal inference in epidemiology. Epidemiology. 2000;11:550-60.

22. Johnson ML, Crown W, Martin BC, Dormuth CR, Siebert U. Good research practices for comparative effectiveness research: analytic methods to improve causal inference from nonrandomized studies of treatment effects using secondary data sources: the ISPOR Good Research Practices for Retrospective Database Analysis Task Force Report-Part III. Value Health. 2009;12:1062-73.

23. Kosanke J, Bergstralh E: GMATCH macro for SAS. http://www.mayo.edu/research/departments-divi sions/department-health-sciences-research/divisionbiomedical-statistics-informatics/software/locallywritten-sas-macros. Accessed Oct 17, 2016.

24. Apperloo AJ, de Zeeuw D, de Jong PE. A short-term antihypertensive treatment-induced fall in glomerular filtration rate predicts long-term stability of renal function. Kidney Int. 1997;51:793-7.

25. Maschio G, Alberti D, Janin G, et al. Effect of the angiotensin-converting-enzyme inhibitor benazepril on the progression of chronic renal insufficiency.

The 
Angiotensin-Converting-Enzyme Inhibition in Progressive Renal Insufficiency Study Group. N Engl J Med. 1996;334(15):939-45.

26. Higashi Y, Oshima T, Sasaki S, Nakano Y, Kambe M, Matsuura H, Kajiyama G. Angiotensin-converting enzyme inhibition, but not calcium antagonism, improves a response of the renal vasculature to L-arginine in patients with essential hypertension. Hypertension. 1998;32:16-24.

27. Ohishi M, Takeya Y, Tatara Y, et al. Strong suppression of the renin-angiotensin system has a renal-protective effect in hypertensive patients: high-dose ARB with ACE inhibitor (Hawaii) study. Hypertens Res. 2010;33:1150-4.

28. Imai E, Horio M, Yamagata $\mathrm{K}$, et al. Slower decline of glomerular filtration rate in the Japanese general population: a longitudinal 10-year follow-up study. Hypertens Res. 2008;31(3):433-41.

29. Vupputuri S, Batuman V, Muntner P, et al. Effect of blood pressure on early decline in kidney function among hypertensive men. Hypertension. 2003;42(6):1144-9. 